\title{
Nature as Ally in Our Chronic Disease Epidemic
}

\section{Anna O'Malley}

Natura Institute for Ecology and Medicine, Commonweal Garden, Bolinas, California, USA.

\section{Abstract}

Our global community is facing a burgeoning and costly chronic disease epidemic. Apparent societal and behavioral drivers of this epidemic create an inflammatory milieu within the human body, a common pathophysiologic hallmark of a majority of chronic diseases. An epidemic of health care provider burnout is simultaneously occurring, and the limitations of our health care system are increasingly apparent. The restorative ways in which nature supports humans and their behaviors, as well as the way nature decreases systemic inflammation and supports the immune system, present an intriguing opportunity to develop models of care that allow for more exposure to and partnership with the natural world. This article articulates the urgent need for collective course change and the evidence base in support of nature as ally in healing work, and considers potential pathways forward. Key Words: NatureMedicine-Chronic disease-Physician burnout-Inflammation.

\section{Introduction}

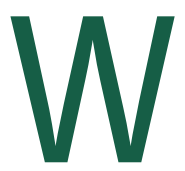

e are living at a time in which healing on many levels is needed. We are in the midst of an epidemic of chronic disease, which is creating great suffering and early mortality, as well as escalating expenditures and mounting pressures on those working within the health care realm. We are increasingly estranged from the natural world, resulting in ecological degradation, loss of connection with that which is soothing and healing in so many ways, and loss of understanding, even, of what we have lost. We are living in a society marred by great socioeconomic disparities and injustice, psychosocial stress, social isolation and loneliness, and accumulating environmental toxicity.
The majority of us live and work within structures and systems that are outmoded in their predication on the fantasy of infinite economic growth on a finite planet, reckless in promoting, overtly or implicitly, consumerism, and ill-equipped to respond to the change that is needed. It is a time that invites radical innovation, informed by a clear-eyed understanding of that which is at the root of our collective unwellness and the drivers thereof, the risks of continuing on this course, and the great potential of aligning our therapeutic efforts with the healing grace of the natural world.

In this article, I offer a review of the literature elucidating the societal, environmental, and behavioral underpinnings of our chronic disease epidemic, with an emphasis on the resultant physiologic mechanisms that are increasingly understood as the common drivers of chronic disease. I will review the projections that reveal the economic peril of our current trajectory, as well as the poignant tragedy that is the epidemic of physician burnout and suicide. Further, I will review the data regarding the risks, on individual and ecological levels, inherent with engaging with the allopathic medical system, as well as the increasing understanding that new models of care are needed, at scale, to do the essential, humane, ecologically responsible and cost-saving work of preventative and community medicine.

This article juxtaposes the aforementioned, primarily anthropogenic, or human-created, realities with that which is known about the myriad ways in which nature, including aspects of our own human nature, is healing. It highlights the intriguing way in which "nature doing what nature does" or "nature naturing," referred to in the Middle Ages as natura naturans, is a healing balm for that which humans have wrought.

I conclude with reflections on the potential of transdisciplinary partnerships and new models of care that are emerging, informed by the pressing need and the inspiring potential. I will offer reflections from professional and personal experience in developing and working with nature-connected healing programs as an integrative family and community medicine physician in Northern California 


\section{NATURE AS ALLY IN OUR CHRONIC DISEASE EPIDEMIC}

and as the director of a nonprofit program exploring the intersection of healing, nature, and ecology.

\section{Our Chronic Disease Epidemic}

We are in the midst of a costly global epidemic of chronic, "noncommunicable" disease. In the United States, 45\% of Americans suffer from one or more "chronic diseases" such as hypertension, diabetes, heart disease, stroke, cancer, or chronic obstructive pulmonary disease (AARP, n.d.). Rates of obesity in the United States have been steadily rising. In 2015-2016 (the last year from which we have data), 39.8\% of adults were obese, and 20.9\% of adolescents between the age of 12 and 19 were obese (Hales, Carroll, Fryar, \& Ogden, 2017), which is, itself, a risk factor for chronic disease (Lakerveld \& Mackenbach, 2017; WHO, 2016). As rates of obesity rise, we can anticipate an attendant rise in rates of chronic disease. Further, chronic diseases such as diabetes and hypertension increase the risk of mortality from infectious disease such as COVID-19.

Our epidemic of obesity and chronic disease has arisen out of a sociocultural milieu that creates unnatural, inflammatory forces and sustained stress on our beings. We are increasingly understanding the link between chronic, systemic inflammation and the development and progression of chronic disease (Hotamisligil, 2006, 2017; Libby, 2007), including heart disease (Cesari et al., 2003), vascular disease and stroke, dementia, hypertension, cancer, asthma (Murdoch \&t Lloyd, 2010), obesity (Hamer \& Stamatakis, 2008), and mental health issues including depression (Hamer, Molloy, de Oliveira, \&t Demakakos, 2009), anxiety (Salim, Chugh, \& Asghar, 2012), and suicidality (Brundin, Bryleva, \&t Thirtamara Rajamani, 2017). Dysregulated inflammatory release of cytokines, known as "cytokine storm," play a role in critical illness due to COVID-19, as well (Xu et al., 2020).

Governed by the immune system, under "acute" circumstances like injury or infection, the body releases chemical mediators of inflammation that aid in responding to and resolving the problem. However, when the inflammatory stimulus is chronic, such as in the case of chronic stress, sedentary lifestyle (Henson et al., 2013), poor diet (Silveira et al., 2018), environmental toxicity (Thompson et al., 2015), social isolation (Yang, McClintock, Kozloski, \& Li, 2013), or living out of synch with natural sleep/wake cycles, a chronic, low-grade systemic inflammation results (Liu, Wang, \& Jiang, 2017). When considering what is known about the drivers of chronic, systemic inflammation, an association with "anthropogens," defined as "manmade environments, their by-products, and/or lifestyles encouraged by these," emerges (Egger, 2012; Egger \& Dixon, 2014). We are living in an "obesogenic" sociocultural environment (Swinburn, Egger, \&
Raza, 1999) that not only favors a sedentary lifestyle; it also drives escalating obesity and chronic disease rates through encouraging overconsumption of "consumer goods" including processed, refined, chemical-laden substances that, when eaten, create inflammation and obesity (Barbaresko, Koch, Schulze, \&t Nothlings, 2013; Calder et al., 2011; Egger, 2009). Further, the profound socioeconomic disparities and the co-occurring stress fans the flames of inflammation, allostatic stress load, and compensatory behaviors and, thus, disease (Gruenewald, Cohen, Matthews, Tracy, \&t Seeman, 2009; Kavanagh et al., 2010; Kim, Jee \& Pikhart, 2018). Understanding the complexity of the upstream causes of chronic disease is essential in considering effective ways to address it and prevent its formation in the first place.

This rise in chronic disease not only impacts quality of life and mortality-it is also financially costly. It is estimated that approximately $90 \%$ of the health care expenditures in our country go toward treating chronic, noncommunicable diseases (Buttorff, Ruder, \& Bauman, 2017). Given the projected increase in disease burden, aging demographic, and rising cost of medical care, federal health care expenditures are projected to rise by $5.5 \%$ annually (CMS, 2020), at a greater rate than the GDP is expected to grow. In 2018, national health expenditures were $\$ 3.6$ trillion, accounting for $17.7 \%$ of the GDP. By 2027, it is projected to reach nearly $\$ 6.0$ trillion and represent 19.4\% of the GDP (CMS, 2020). Expenditures are increasing on the individual level, as well. Since 2000, health insurance premiums for employer-sponsored health coverage have increased by 87\% (Hoffman, n.d.). These increases are not sustainable for individuals, families, employers, or our country.

\section{Concurrent Challenges within the Health Care System}

The increasing burden of disease puts additional pressure on our health care system and on our already strained health care providers. In what many are calling a "public health crisis" (Noseworthy et al., 2017), a staggering number (51\%) of surveyed physicians experience burnout (Peckham, 2017). The 2018 Survey of America's Physicians Practice Patterns and Perspectives found that 78\% of surveyed physicians experienced professional "burnout," defined as a loss of satisfaction and sense of efficacy at least some of the time, up 4\% from the previous 2016 survey (Hawkins, 2018). Physicians experiencing burnout often curtail work hours or leave practice. In fact, the US Department of Health and Human Services has predicted a shortage of 90,000 physicians by the year 2025, driven in large part by epidemic burnout (Shanafelt, Dyrbye, West, \& Sinsky, 2016). Additionally, physicians die by suicide at a rate higher than the 


\section{O’MALLEY}

general population (Schernhammer \&t Colditz, 2004), under the pressure of workload, ever-increasing administrative tasks, work inefficiency, loss of autonomy and meaning in work, and the challenge of balancing work and home responsibilities, compounded by unaddressed mental health challenges (West, Dyrbye, \& Shanafelt, 2018).

\section{Risks Inherent in Engaging with the Medical System}

The consequences of burned-out health care providers exacerbate the already risky proposition of engaging with the health care system. By some estimates, the third leading cause of death in the United States is medical error (Makary \& Michael, 2016). And, while that estimate may be high (Shojania \& Dixon-Woods, 2017), there is certainly risk inherent in receiving care in a system in which visits are short and rushed, systemic distractions abound, and multiple medicines are prescribed for several conditions in one patient (Kohn, Corrigan, \&t Donaldson, 2000).

In addition to the aforementioned risks of our current epidemic unwellness, there is ecological risk in over-relying on downstream "fixes," such as pharmaceuticals and procedures, to these conditions. The ecological footprint of allopathic medicine is great: $8 \%$ of $\mathrm{CO}_{2}$ emissions in the United States are from the health care industry (Chung \& Meltzer, 2009; Eckelman \& Sherman, 2016). Active pharmaceutical ingredients that reach our ground and surface water impact aquatic creatures and humans alike (Küster \&t Adler, 2014). The more we can do to prevent or reduce the need for ecologically costly and inherently risky use of pharmaceuticals, surgical procedures, and inpatient hospitalization, the better-for patients and for the rest of the world.

As a female primary care physician with two young children (a demographic with a particularly high risk of burnout), peering into the future of my profession and the intertwined challenges of rising rates of human unwellness and ecological collapse, I know from a place of deeply felt personal experience that change must happen. As a lover of nature and as someone who has received much restoration and revitalization through my relationship with the natural world, I am intrigued by the ways in which this healing relationship works and am inspired by the potential in allowing the healing wisdom of nature to inform innovation in our approach to the art and practice of medicine.

\section{Nature as Healer}

The literature on the myriad ways in which nature has a restorative, health-promoting effect on our human beings is extensive and clear. Perhaps it should not come as a surprise, given that we humans have evolved within a natural context, that this is so. After all, we are also of nature and have the same capacity for homeostasis, selfhealing, and regeneration as other natural systems do. Viewed through the lens of the foregoing contextualization of our burgeoning chronic disease epidemic and the anthropogenic drivers thereof, the mechanisms by which nature appears to be healing us are particularly relevant.

The human-nature relationship is complex and rooted in a long coevolutionary process. The practice of science applied to studying this relationship is inherently reductionistic, and the understanding of what is at play is thus iterative and incomplete. However, what is emerging is compellingly therapeutic for the physiological and psychological ravages of living in the modern, post-industrial society.

\section{Nature Naturing: Decreasing Inflammation and Stress, Strengthening Connection}

Being in nature decreases the risk of chronic disease (Brown et al., 2016). From decreasing blood pressure (Mao et al., 2012) and risk of cardiovascular disease (Li et al., 2011) to improving blood sugar (Ohtsuka, Yabunaka, \&t Takayama, 1998), decreasing anxiety and depression (Capaldi, Dopko, \&t Zelenski, 2014), improving chronic pain (Han et al., 2016), and decreasing obesity (Lachowycz \& Jones, 2011), nature exposure consistently improves outcomes and biochemical intermediaries of chronic disease processes. With such a complex "intervention," there are many facets to appreciate and mechanisms to query (Frumkin et al., 2017). Intriguingly, the mechanisms by which nature heals through so many points of engagement oppose in mirrorlike fashion the mechanisms by which anthropogens drive chronic disease: by mediating the immune response, decreasing inflammation, and decreasing the chronic stress response, which in turn mediates metabolic and inflammatory pathways (Bhasin et al., 2013; Kenney \&t Ganta, 2014; Kuo, 2015).

Consider a walk in the woods. Think back to the curiosity and wonder-infused, fully present way you engaged the natural world as a child. Feel the fresh breeze on your face; hear it as it whispers through the trees. Notice the way the forest smells, the scent of the trees ... breathe in the aromatic essential oils released by the trees (those "phytoncides" that the tree gives off to bolster its own health, ward against infection, while tending the health of its community: the other trees and beings in the forest). Notice the way you feel as you take a deep breath in. As the phytoncides are breathed in and absorbed across the lining of the lungs, they are engaged by receptors that trigger a cascade of chemical changes that increase protective natural killer cells, thereby strengthening your immune function and 


\section{NATURE AS ALLY IN OUR CHRONIC DISEASE EPIDEMIC}

lowering your risk of cancer (Imai, 2000), as well as lowering stress hormone levels (Li et al., 2006, 2009, 2010). Allow your gaze to be drawn by some facet of the intricate perfection of the natural world on display. Perhaps you feel affectionate wonder while marveling at the turret spider's amazing construction, down on the forest floor, or at seeing a mushroom beginning to push its way out of the duff. Let yourself resonate with the awe of observing the natural world doing what it does. This emotional state further diminishes inflammatory cytokines in your body (Stellar et al., 2015), supporting the health of every part of your body and decreasing risk of developing disease. Perhaps you stand in awe as a shaft of light imbues a glade with a celestial beauty, feeling connected to that which is greater than yourself (Shiota, Keltner, \& Mossman, 2007). Your existential capacity to connect with meaning (Li, Dou, Wang, \& Nie, 2019), with the perspective born of understanding the smallness of self, and with the "prosocial" drive to connect with and help others (Piff, Dietze, Feinberg, Stancato, \& Keltner, 2015; Zhang, Piff, Iyer, Koleva, \&t Keltner, 2014) becomes heightened, while distracted, materialistic thoughts subside (Jiang, Yin, Mei, Zhu, \&t Zhou, 2018; Rudd, Vohs, \& Aaker, 2012). Allow yourself to be moved by the beauty of the backlit dew on an intricate spiderweb, or in the astonishing fractal patterns in the seed cone you pick up, or the branching pattern in the leaves, the branches, the bark. Our human souls are nourished by beauty; our physiologic capacity to be nourished by nature is impacted by the degree to which we let the beauty of nature move us (Richardson \& McEwan, 2018; Zhang, Howell, \& Iyer, 2014). Our experience of connection with nature is deepened by the emotional response to the beauty therein (Lumber, Richardson, \& Sheffield, 2017), and this connectedness supports emotional well-being (Capaldi et al., 2014). The stress held in the body, the so-called "allostatic load," is lightened (Gladwell et al., 2012), and wellness-supporting feelings of aliveness and vitality arise (Ryan et al., 2010). As we receive the healing benefits of being in the natural world, so too are we moved to appreciate and protect it (Whitburn, Linklater, \& Abrahamse, 2019).

Nature is a compelling antidote to the toxic physiologic effect of living in the stressful, inflammatory, distracted, and disconnected consumer culture. Nature's ability to support our "prosocial” human capacity for connection, helpfulness, and empathy is an important aspect of this medicine (Guéguen \& Stefan, 2014). At a time when social isolation is epidemic (Holt-Lunstad, 2017; Wilson \& Moulton, 2010) and loneliness recognized as an important risk factor for disease and mortality (Holt-Lunstad, Smith, \& Layton, 2010), supporting our human capacities for connection is highly relevant. Having close, supportive relationships lowers markers of inflammation (Fagundes, Bennett, Derry, \&t Kiecolt-Glaser, 2011; Kiecolt-Glaser, Gouin, \&t
Hantsoo, 2010) and results in a 50\% reduction in mortality (HoltLunstad et al., 2010). Having a close, supportive relationship with the natural world results both in increased health and improved capacity to have close, supportive relationships with other human beings.

\section{Looking Forward, Allied with Nature}

It is clear there is an imperative to change our course. Our current trajectory of escalating rates of chronic, noncommunicable disease, with attendant human, ecological, and financial costs, is unsustainable. Upstream, preventative efforts that support behavior change and wellness on multiple levels are essential in correcting course (Hoffman, n.d.; Mays \& Smith, 2011; Milstein, Homer, Briss, Burton, \& Pechacek, 2011). Greening the practice of medicine through the development of community-level models that partner with the healing grace of the natural world to effect behavior change may be an important component to working toward the "quadruple aim”: enhancing patient experience, improving population health, reducing costs, and improving the work life of health care clinicians and staff (Bodenheimer \& Sinsky, 2014). Perhaps the aim should be explicitly "quintuple": accomplishing these four goals while minimizing ecological harm.

This moment also invites those of us engaged in the practice of medicine to reflect upon what it means to be a healer, to truly aim for the "non-maleficence" or "non-harm-doing" to which we solemnly pledge, and to have a more complete understanding of the importance of interrelatedness in our healing work. Attuning ourselves to an ecological orientation in our practice-from a consideration of the impact of the pharmaceuticals we prescribe to the degree to which we are complicit in ecological degradation by keeping our focus on downstream, costly fixes-is important. Advocating for opportunities to engage in creative, professionally satisfying upstream healing work within our communities diminishes risk of burnout and is an important part of the restoration of the role of physician/healer in society. Doing so in a way that also repairs our relationship with the natural world yields benefits for our patients, our communities, ourselves, and for the natural world herself.

As a primary care provider practicing medicine within a Federally Qualified Health Center-a part of the vitally important national network of community health centers providing care to all people, regardless of ability to pay-while also directing a nonprofit program situated within a National Park, I see great potential for creative innovation within such existing structures. Questions arise: How might mutually beneficial alliances emerge between those of us practicing medicine-particularly those at the "front-lines," doing the work of primary care, charged with guiding people toward wellness, 


\section{O’MALLEY}

preventing disease, and slowing the progression of chronic illnessand those stewarding land in the public, private, and nonprofit sector? How might our preventative medicine strategies be "greened," infused with what 12th-century abbess Hildegard von Bingen called "veriditas," or the divine healing power of nature? How can those of us practicing family and community medicine intentionally leverage community and interconnectedness as medicine and widen the definition of community to include those beings in the natural world as well? How might therapeutic, group interventions with an integrative, ecological, preventative focus take place out in the natural world, so that we are fully supported in our healing work, patients and health care practitioner alike? How might transdisciplinary partnerships between those engaged in the work of connecting people to the natural world-from ecopsychologists and ecotherapists, natural historians and ecologists, to those in medicine-be cultivated and therapeutically applied?

I am deeply grateful to be in a position to facilitate collaboration between the community health center in which I practice medicine and the Commonweal Garden, which I steward and in which I direct a nonprofit program, Natura Institute for Ecology and Medicine, exploring the medicine of connection: to oneself, each other, and the earth. While my circumstances are unique, much of what we are doing in the garden (and the surrounding wilderness of the Point Reyes National Seashore) could be replicated in other community health center public or private land-based partnerships. Our core programs leverage connection to nature in support of personal health and healing and reparation of our relationship with the natural world, and include

- Ecologically attuned integrative medicine circles exploring how to support our "natural" beings in finding balance in relationship to self, our behaviors, and the natural world. We explicitly link behavioral choices, attunement to natural rhythms, and ecological consciousness with the health and optimal function of our human systems, such as the immune system, gastrointestinal system, cardiovascular system, mental well-being, healthy sleep, and so on. We aim to empower individuals to make ecologically conscious and health-supporting behavioral choices and to build a community culture around health, vitality, and nature connection. This is greatly facilitated and augmented by our natural setting.

- Retreat-like programs for people to come together seasonally over one year, learning to nourish mind, body, and spirit while cultivating supportive peer relationships and a deepened relationship with nature and place. Through curricular elements and home assignments including regular "nature sits" and the social sharing of photos from our home nature experiences, the practice of nature connection as an integral part of health optimization is underscored. Seasonal attunement offers the opportunity for us to appreciate how inextricably linked we are to nature and that we are, indeed, of nature. This understanding leads to behavioral choices that support the health and wellbeing of our body, as well as "our bigger body," the earth.

- Programs exploring personal and community health and resilience through skill-building in "permaculture" design and ecological restoration, food growing, herbal medicine-making, and health sovereignty for adults and children.

- Restorative retreats for physicians, physicians in training, and medical students with explicit experiential learning regarding the healing and restorative power of nature.

- Modeling and elaborating the leadership role that community physicians can play in elevating the importance of ecological consciousness and nature connection, through written work including newspaper contributions, radio appearances, regular community talks, and chef demonstrations.

On a personal level, from the perspective of a healer, advocating for ways of living and being that are beneficial to ourselves, our communities, and the living, breathing earth is joyful, timely, and deeply meaningful. It invites further collaboration and mutual support.

\section{Acknowledgments}

I'd like to acknowledge James Stark for his collaborative and supportive mentorship, Michael Lerner and Oren Slozberg of Commonweal for their supportive leadership, and Steven Siegel of Coastal Health Alliance for support of community-level, upstream, and innovative approaches to medicine. I'd also like to acknowledge Thomas Fleischner and Laura Sewall for the invitation into a transdisciplinary dialogue in support of Nature.

\section{Author Disclosure Statement}

No competing financial interests exist.

\section{Funding Information}

No funding was received for this article.

\section{REFERENCES}

AARP. (n.d.) Chronic conditions among older Americans. Washington, DC: American Association of Retired Persons. Retrieved from https://assets.aarp.org/rgcenter/ health/beyond_50_hcr_conditions.pdf 
NATURE AS ALLY IN OUR CHRONIC DISEASE EPIDEMIC

Barbaresko, J., Koch, M., Schulze, B., Et, Nothlings, U. (2013). Dietary pattern analysis and biomarkers of low-grade inflammation: A systematic literature review. Nutrition Reviews, 71, 511-527.

Bhasin, M. K., Dusek, J. A., Chang, B., Joseph, M. G., Denninger, J. W., Fricchione, G.L., ... Libermann, T. A. (2013). Relaxation response induces temporal transcriptome changes in energy metabolism, insulin secretion and inflammatory pathways. PLoS One, 8, doi:10.1371/journal.pone.0062817

Bodenheimer, T., \& Sinsky, C. (2014). From triple to quadruple aim: Care of the patient requires care of the provider. Annals of Family Medicine, 12, 573-576.

Brown, S. C., Lombard, J., Wang, K., Byrne, M. M., Toro, M., Plater-Zyberk, E., ... Szapocznick, J. (2016). Neighborhood greenness and chronic health conditions in Medicare beneficiaries. American Journal of Preventive Medicine, 51, 78-89.

Brundin, L., Bryleva, E. Y., \& Thirtamara Rajamani, K. (2017). Role of inflammation in suicide: From mechanisms to treatment. Neuropsychopharmacology, 42, 271-283.

Buttorff, C., Ruder, T., \&t Bauman, M. (2017). Multiple chronic conditions in the United States. Santa Monica, CA: RAND Corporation. Retrieved from https:// www.rand.org/content/dam/rand/pubs/tools/TL200/TL221/RAND_TL221.pdf

Calder, N., Ahluwalia, F., Brouns, F., Buetler, T., Clement, K., Cunningham, K., ... Esposito, K. (2011). Dietary factors and low-grade inflammation in relation to overweight and obesity. British Journal of Nutrition, 106, doi:10.1017/ s0007114511005460

Capaldi, C. A., Dopko, R. L., \& Zelenski, J. M. (2014). The relationship between nature connectedness and happiness: A meta-analysis. Frontiers in Psychology, 5, doi:10.3389/fpsyg.2014.00976

Cesari, M., Penninx, B. W., Newman, A. B., Kritchevsky, S. B., Nicklas, B. J., SuttonTyrrell, K., ... Pahor, M. (2003). Inflammatory markers and onset of cardiovascular events: Results from the Health ABC study. Circulation, 108, 2317-2322.

Chung, J. W., \&t Meltzer, D. O. (2009). Estimate of the carbon footprint of the US health care sector. JAMA: The Journal of the American Medical Association, 302, 1970-1972.

CMS. (2020). NHE fact sheet. Baltimore: MD: Centers for Medicare and Medicaid Services. Retrieved from https://www.cms.gov/Research-Statistics-Data-andSystems/Statistics-Trends-and-Reports/NationalHealthExpendData/NHE-FactSheet

Eckelman, M. J., \& Sherman, J. (2016). Environmental impacts of the U.S. health care system and effects on public health. PLoS One, 11, doi:10.1371/ journal.pone.0157014

Egger, G. (2009). Health, "illth" and economic growth: Medicine, environment and economics at the cross-roads. The American Journal of Preventive Medicine, $37,78-83$.

Egger, G. (2012). In search of a germ theory equivalent for chronic disease. Preventing Chronic Disease, 9, doi:10.5888/pcd9.110301

Egger, G., \&t Dixon, J. (2014). Beyond obesity and lifestyle: A review of 21st century chronic disease determinants. BioMed Research International, 2014, doi:10.1155/2014/731685

Fagundes, C. P., Bennett, J. M., Derry, H. M., \&t Kiecolt-Glaser, J. K. (2011). Relationships and inflammation across the lifespan: Social developmental pathways to disease. Social and Personality Psychology Compass, 5, 891-903.

Frumkin, H., Bratman, G. N., Breslow, S. J., Cochran, B., Kahn, P. H., Jr., Lawler, J. J., ... Wood, S. A. (2017). Nature contact and human health: A research agenda. Environmental Health Perspectives, 125, doi:10.1289/EHP1663
Gladwell, V. F., Brown, D. K., Barton, J. L., Tarvainen, M. P., Kuoppa, P., Pretty, J., ... Sandercock, G. R. H. (2012). The effects of views of nature on autonomic control. European Journal of Applied Physiology, 112, 3379-3386.

Gruenewald, T. L., Cohen, S., Matthews, K. A., Tracy, R., \&t Seeman, T. E. (2009). Association of socioeconomic status with inflammation markers in Black and White men and women in the Coronary Artery Risk Development in Young Adults (CARDIA) study. Social science \&t Medicine, 69, 451-459.

Guéguen, N., and Stefan, J. (2014). "Green altruism": Short immersion in natural environments and helping behavior. Environment and Behavior, 48, doi:10.1177/0013916514536576

Hales, C. M., Carroll, M. D., Fryar, C. D., \& Ogden, C. L. (2017). Prevalence of obesity among adults and youth: United States, 2015-2016 (NCHS data brief, 288). Hyattsville, MD: National Center for Health Statistics.

Hamer, M., Molloy, G. J., de Oliveira, C., \&t Demakakos, P. (2009). Persistent depressive symptomatology and inflammation: To what extent do health behaviours and weight control mediate this relationship?. Brain, Behavior, and Immunity, 23, 413-418.

Hamer, M., \& Stamatakis, E. (2008). Inflammation as an intermediate pathway in the association between psychosocial stress and obesity. Physiology and Behavior, 94, 536-539.

Han, J. W., Choi, H., Jeon, Y. H., Yoon, C. H., Woo, J. M., Kim, W. (2016). The effects of forest therapy on coping with chronic widespread pain: Physiological and psychological differences between participants in a forest therapy program and a control group. International Journal of Environmental Research and Public Health, 13, doi:10.3390/ijerph13030255

Hawkins, M. (2018). 2018 Survey of America's physicians: Practice patterns \& perspectives. The Physicians Foundation. Retrieved from https://physicians foundation.org/wp-content/uploads/2018/09/physicians-survey-results-final2018.pdf

Henson, J., Yates, T., Edwardson, C. L., Khunti, K., Talbot, D., Gray, L. J., \&t Davies, M. J. (2013). Sedentary time and markers of chronic low-grade inflammation in a high risk population. PLoS One, 8, doi:10.1371/journal.pone.0078350

Hoffman, D. (n.d.). National Association of Chronic Disease Directors: Why public health is necessary to improve healthcare (White paper). Atlanta, GA: National Association of Chronic Disease Directors. Retrieved from https://cdn.ymaws .com/www.chronicdisease.org/resource/resmgr/white_papers/cd_white_paper_ hoffman.pdf

Holt-Lunstad, J. (2017). The potential public health relevance of social isolation and Ioneliness: Prevalence, epidemiology, and risk factors. Public Policy \& Aging Report, 27, 127-130.

Holt-Lunstad, J., Smith, T.B., \& Layton, B. (2010). Social relationships and mortality risk: A meta-analytic. PLoS Medicine, 7, doi:10.1371/journal.pmed .1000316

Hotamisligil, G. (2006). Inflammation and metabolic disorders. Nature, 444, 860867.

Hotamisligil, G. (2017). Inflammation, metaflammation and immunometabolic disorders. Nature, 542, 177-185.

Imai, K., Matsuyama, S., Miyake, S., Suga, K., \&t Nakachi, K. (2000). Natural cytotoxic activity of peripheral-blood lymphocytes and cancer incidence: An 11-year follow-up study of a general population. Lancet, 356, 17951799.

Jiang, L., Yin, J., Mei, D., Zhu, H., \& Zhou, X. (2018). Awe weakens the desire for money. Journal of Pacific Rim Psychology, 12, doi:10.1017/prp.2017.27 


\section{O’MALLEY}

Kavanagh, A., Bentley, R., Turrell, G., Shaw, J. Dunstan, D., \& Subramanian, S. V. (2010) Socioeconomic position, gender, health behaviours and biomarkers of cardiovascular disease and diabetes. Social Science \&t Medicine, 71, 1150-1160.

Kenney, M. J., \& Ganta, C. K. (2014). Autonomic nervous system and immune system interactions. Comprehensive Physiology, 4, 1177-1200.

Kiecolt-Glaser, J. K., Gouin, J. P., \& Hantsoo, L. (2010) Close relationships, inflammation, and health. Neuroscience and Biobehavioral Reviews, 35, 33-38.

Kim, G. R., Jee, S. H., \& Pikhart, H. (2018). Role of allostatic load and health behaviours in explaining socioeconomic disparities in mortality: A structural equation modelling approach. Journal of Epidemiology and Community Health, 72, 545-551.

Kohn, L. T., Corrigan, J., \& Donaldson, M. S. (2000). To err is human: Building a safer health system. Washington, DC: National Academies Press.

Kuo, M. (2015). How might contact with nature promote human health? Promising mechanisms and a possible central pathway. Frontiers in Psychology, 6, doi:10.3389/fpsyg.2015.01093

Küster, A., \&t Adler, N. (2014). Pharmaceuticals in the environment: Scientific evidence of risks and its regulation. Philosophical Transactions of the Royal Society of London. Series B, Biological Sciences, 369, doi:10.1098/rstb .2013 .0587

Lachowycz, K., \& Jones, A.P. (2011). Greenspace and obesity: A systematic review of the evidence. Obesity Reviews, 12, doi10.1111/j.1467-789X.2010.00827.x

Lakerveld, J., \& Mackenbach, J. (2017). The upstream determinants of adult obesity. Obesity Facts, 10, 216-222.

Li, J. J., Dou, K., Wang, Y. J., \& Nie, Y. G. (2019). Why awe promotes prosocial behaviors? The mediating effects of future time perspective and selftranscendence meaning of life. Frontiers in Psychology, 10, doi:10.3389/ fpsyg.2019.01140

Li, Q., Kobayashi, M., Inagaki, H., Hirata, Y., Hirata K., Li Y. J., ... Kagawa, T. (2010). A day trip to a forest park increases human natural killer activity and the expression of anti-cancer proteins in male subjects. Journal of Biological Regulators and Homeostatic Agents, 24, 157-165.

Li, O., Kobayashi, M., Wakayama, Y., Inagaki, H., Katsumata, M., Hirata, Y., ... Miyazaki, Y. (2009). Effect of phytoncide from trees on human natural killer cell function. International Journal of Immunopathology and Pharmacology 22, 951-959.

Li, O., Nakadai, A., Matsushima, H., Miyazaki, Y., Krensky, A.M., Kawada, T., ... Morimoto, K. (2006). Phytoncides (wood essential oils) induce human natural killer cell activity. Immunopharmacology and Immunotoxicology, 28, 319-333.

Li, Q., Otsuka, T., Kobayashi, M., Wakayama, Y., Inagaki, H., Katsumata, M., ... Kagawa, T. (2011). Acute effects of walking in forest environments on cardiovascular and metabolic parameters. European Journal of Applied Physiology, 111, 2845-2853.

Libby, P. (2007). Inflammatory mechanisms: The molecular basis of inflammation and disease. Nutrition Reviews, 65, S140-S146.

Liu, Y. Z., Wang, Y. X., \&t Jiang, C. L. (2017). Inflammation: The common pathway of stress-related diseases. Frontiers in Human Neuroscience, 11, doi:10.3389/ fnhum.2017.00316

Lumber, R., Richardson, M., \& Sheffield, D. (2017). Beyond knowing nature: Contact, emotion, compassion, meaning, and beauty are pathways to nature connection. PLoS One, 12, doi:10.1371/journal.pone.0177186

Makary, M., \& Michael, D. (2016). Medical error-the third leading cause of death in the US. BMJ, 353, doi:10.1136/bmj.i2139
Mao, G., Cao, Y., Lan, X., He, Z., Chen, Z., Wang, Y., ... Yan, J. (2012). Therapeutic effect of forest bathing on human hypertension in the elderly. Journal of Cardiology, 60, 495-502.

Mays, G., \& Smith, S. (2011). Evidence links increases in public health spending to declines in preventive deaths. Health Affairs, 30, 1585-1593.

Milstein, B., Homer, J., Briss, P., Burton, D., \& Pechacek, T. (2011). Why behavioral and environmental factors are needed to improve health at lower cost. Health Affairs, 30, 823-832.

Murdoch, J. R., \& Lloyd, C. M. (2010). Chronic inflammation and asthma. Mutation Research, 690, 24-39.

Noseworthy, J., Madara, J., Cosgrove, D., Edgeworth, M., Ellison, E., Krevans, S., ... Harrison, D. (2017, March 28). Physician burnout is a public health crisis: A message to our fellow health care CEOs. Health Affairs Blog. Retrieved from https://www.healthaffairs.org/do/10.1377/hblog20170328.059397/full

Ohtsuka, Y., Yabunaka, N., Takayama, S. (1998). Shinrin-yoku (forest-air bathing and walking) effectively decreases blood glucose levels in diabetic patients. International Journal of Biometeorology, 41, 125-127.

Peckham, C. (2017, January 11). Lifestyle report 2017: Race and ethnicity, bias and burnout. Medscape. Retrieved from https://www.medscape.com/features/ slideshow/lifestyle/2017/overview

Piff, P. K., Dietze, P., Feinberg, M., Stancato, D. M., \& Keltner, D. (2015). Awe, the small self, and prosocial behavior. Journal of Personality and Social Psychology, 108, 883-899.

Richardson, M., \& McEwan, K. (2018). 30 days wild and the relationships between engagement with nature's beauty, nature connectedness and well-being. Frontiers in Psychology, 9, doi:10.3389/fpsyg.2018.01500

Rudd, M., Vohs, K. D., \& Aaker, J. (2012). Awe expands people's perception of time, alters decision making, and enhances well-being. Psychological Science, 23, $1130-1136$.

Ryan, R. M., Weinstein, N., Bernstein, J., Brown, K. W., Mistretta, L., \& Gagne M. (2010). Vitalizing effects of being outdoors and in nature. Journal of Environmental Psychology, 30, 159-168.

Salim, S., Chugh, G., \&t Asghar, M. (2012). Inflammation in anxiety. Advances in Protein Chemistry and Structural Biology, 88, 1-25.

Schernhammer, E. S., \& Colditz, G. A. (2004). Suicide rates among physicians: A quantitative and gender assessment (meta-analysis). American Journal of Psychiatry, 161, 2295-2302.

Shanafelt, T. D., Dyrbye, L. N., West, C. P., \& Sinsky, C. A. (2016). Potential impact of burnout on the US physician workforce. Mayo Clinic Proceedings, 91, 16671668.

Shiota, M. N., Keltner, D., \& Mossman, A. (2007). The nature of awe: Elicitors, appraisals, and effects on self-concept. Cognition and Emotion, 21, 944-963.

Shojania, K. G., \&t Dixon-Woods, M. (2017). Estimating deaths due to medical error: The ongoing controversy and why it matters. BMJ Quality \& Safety, 26, 423-428.

Silveira, B., Oliveira, T., Andrade, P. A., Hermsdorff, H., Rosa, C., \& Franceschini, S. (2018). Dietary pattern and macronutrients profile on the variation of inflammatory biomarkers: Scientific update. Cardiology Research and Practice, doi:10.1155/2018/4762575

Stellar, J. E., John-Henderson, N., Anderson, C. L., Gordon, A. M., McNeil, G. D., Ct Keltner, D. (2015). Positive affect and markers of inflammation: Discrete positive emotions predict lower levels of inflammatory cytokines. Emotion, 15, 129-133. 
NATURE AS ALLY IN OUR CHRONIC DISEASE EPIDEMIC

Swinburn, B., Egger, G., \&t Raza, F. (1999). Dissecting obesogenic environments: The development and application of a framework for identifying and prioritizing environmental interventions for obesity. Preventive Medicine, 29, 563-570.

Thompson, P. A., Khatami, M., Baglole, C. J., Sun, J., Harris, S. A., Moon, E. Y., ... Bisson, W. H. (2015). Environmental immune disruptors, inflammation and cancer risk. Carcinogenesis, 36, doi:10.1093/carcin/bgv038

West, C. P., Dyrbye, L. N., \& Shanafelt, T. D. (2018). Physician burnout: Contributors, consequences and solutions. Journal of Internal Medicine, 283, 516-529.

Whitburn, J, Linklater, W, \& Abrahamse, W. (2019). Meta-analysis of human connection to nature and proenvironmental behavior. Conservation Biology, $34,180-193$

WHO. (2016). Obesity and overweight factsheet. Geneva, Switzerland: World Health Organization. Retrieved from www.who.int/mediacentre/factsheets/fs311/en/

Wilson, C., \& Moulton, B. (2010). Loneliness among older adults: A national survey of adults 45+ (Prepared by Nowledge Networks and Insight Policy Research). Washington, DC: American Association of Retired Persons.

Xu, Z., Shi, L., Wang, Y., Zhang, J., Huang, L., Zhang, C., \&t Tai, Y. (2020). Pathological findings of COVID-19 associated with acute respiratory distress syndrome. The Lancet. Respiratory Medicine, 8, 420-422

Yang, Y. C., McClintock, M. K., Kozloski, M., \& Li, T. (2013). Social isolation and adult mortality: The role of chronic inflammation and sex differences. Journal of Health and Social Behavior, 54, 183-203.
Zhang, J. W., Howell, R. T., \&t lyer, R. (2014). Engagement with natural beauty moderates the positive relation between connectedness with nature and psychological well-being. Journal of Environmental Psychology, 38, 55-63.

Zhang, J. W., Piff, P. K., Iyer, R., Koleva, S., \& Keltner, D. (2014). An occasion for unselfing: Beautiful nature leads to prosociality. Journal of Environmental Psychology, 37, 61-72.

Address correspondence to:

Anna O'Malley

Commonweal Garden

P.O. Box 316

480 Mesa Road

Bolinas, CA 94924

USA

E-mail: anna@naturainstitute.org

Received: March 6, 2020 Accepted: April 14, 2020 